\title{
Induction of Autologous Bone-Marrow Stem Cells by Low-Level Laser Therapy Has Beneficial Effects on the Kidneys Post-Ischemia-Reperfusion Injury in the Rat
}

\author{
Hana Tuby, Lidya Maltz, Uri Oron* \\ Department of Zoology, The George S. Wise Faculty of Life Sciences, Tel-Aviv University, Tel-Aviv, Israel \\ Email: "oronu@post.tau.ac.il
}

Received 7 April 2014; revised 21 May 2014; accepted 1 June 2014

Copyright (C) 2014 by authors and Scientific Research Publishing Inc. This work is licensed under the Creative Commons Attribution International License (CC BY). http://creativecommons.org/licenses/by/4.0/

(c) (i) Open Access

\section{Abstract}

Acute renal failure has a $\mathbf{5 0 \%}-\mathbf{8 0 \%}$ mortality rate. Currently, treatment options for this lifethreatening disease are limited. Low-level laser therapy (LLLT) has been found to modulate biological activity. The aim of the present study was to investigate the possible beneficial effects of laser application to stem cells in the bone marrow, on the kidneys of rats that had undergone ischemia-reperfusion injury (IRI). IRI was induced by occlusion of the renal artery to 3- and 7-month-old rats for 15 or 30 minutes. In an additional experiment IRI was applied to both kidneys for 20 min each in 2-3-month-old rats. Rats were then divided randomly into two groups of control and laser-treated. Laser therapy (Ga-Al-As $810 \mathrm{~nm}, 200 \mathrm{~mW}$ output for $2 \mathrm{~min}$ ) was applied to the bone marrow 1 and 7 days post-IRI to the kidneys, and rats were sacrificed 2 weeks later. Histomorphometry and immunohistochemistry were performed on kidney sections and blood markers for kidney function. Quantitative histomorphometric analysis revealed a reduction in dilatation of the renal tubules, restored structural integrity of the renal tubules, and reduced necrosis in the laser-treated rats as compared to the control, non-laser-irradiated group. C-kit positive cell density in kidneys post-IRI and laser-treatment was significantly $(p=0.015) 3.2$-fold higher compared to the control group. Creatinine and blood urea nitrogen content were significantly lower in the laser-treated rats as compared to control. It is concluded that LLLT application to the bone marrow (BM) causes a significant increase in the density of mesenchymal stem cells in the kidneys post-IRI, probably by induction of stem cells in the BM, which subsequently migrate to the IRI kidney, significantly reducing the pathological features of the kidney and increasing kidney function post IRI.

\footnotetext{
${ }^{*}$ Corresponding author.
} 


\title{
Keywords
}

\author{
Kidney, Mesenchymal Stem Cells (MSCs), Low-Level Laser Therapy (LLLT), Ischemia-Reperfusion \\ Injury (IRI)
}

\section{Introduction}

Acute kidney injury (AKI) is a common clinical issue with high morbidity and mortality. Cell-based therapy offers an exciting potential for kidney regeneration [1]-[10]. In both mice and humans there is evidence that cells of bone marrow (BM) origin take part in tubular epithelium regeneration [1]. Injury to a target organ can be sensed by BM stem cells, which subsequently migrate to the site of damage, undergo differentiation, and promote structural and functional repair. Recent studies have demonstrated that hematopoietic stem cells were mobilized following ischemia/reperfusion injury (IRI) to the kidney, engrafted onto the kidney, and differentiated into tubular epithelium in the areas of damage [2] [3]. The evidence that mesenchymal stem cells, by virtue of their reno-protective property, restore renal tubular structure and renal function during experimental acute renal failure, offers the potential for therapeutic intervention [1]. In addition to the contribution to kidney repair by bone-marrow-derived stem cells, and putative renal tubular epithelial stem cells, the original hypothesis still stands that viable tubular epithelial cells that have survived the ischemic insult, proliferate and thereby generate new tubular epithelial cells that replace the damaged ones [4]. Moreover, injection of stem cells to rats post ischemic insult resulted in a reno-protective capacity of mesenchymal stem cells and indicates the possibility of a cell-based paradigm shift in the treatment of IRI [10]. Wang et al. [5] demonstrated that administration of bone-marrow-derived stem cells suppresses cellular necrosis and apoptosis induced by reperfusion of the ischemic kidney in rats [5]. Stokman et al. [6] demonstrated that in a hypoxia in-vitro model of renal ischemia, stimulation of tubular epithelial cells with cytokine stem cell factor (SCF) activated survival signaling and reduced apoptosis. The involvement of c-kit in the above processes was also established.

Low-level laser therapy (LLLT) has been found to modulate various biological processes, such as increasing mitochondrial respiration and ATP synthesis, facilitating wound healing, and promoting the process of skeletal muscle regeneration and angiogenesis [11]-[16]. In an experimental model of the ischemic/infarcted heart in rats and dogs, it was demonstrated that LLLT application directly to the ischemic area in the heart at optimal power parameters significantly reduced scar tissue formation [17]-[19]. This phenomenon was partially attributed to a significant elevation in ATP content, heat shock proteins, vascular endothelial growth factor (VEGF), inducible nitric oxide (NO) synthase, and angiogenesis in the ischemic zone of the laser-irradiated rats, as compared to non-irradiated rats [20]. The effect of LLLT on chronic kidney disease has not been extensively studied. Oliveire et al. [21], in a model of unilateral obstruction demonstrated that LLLT has a protective effect regarding renal interstitial fibrosis through attenuating inflammation. There are also several reports on the effects of photobiostimulation on stem cells or progenitor cells. LLLT application to normal human neural progenitor cells significantly increased ATP production in these cells [22]. LLLT delivery to mesenchymal stem cells (MSCs) and cardiac stem cells in vitro caused a significant enhancement in their proliferation rate [23] [24] and also increased the proliferation rate of adipose-derived stem cells in vitro [25]. Recently, it was demonstrated that LLLT application to autologous BM can induce proliferation and recruitment of MSCs to the infarcted rat heart, markedly reduce scarring [26] [27], and induce cardiogenesis along the border line of the infarcted area [28].

The aim of the present study was to investigate the possibility that induction of stem cells in the BM of rats by LLLT also has beneficial effects following IRI to the kidneys.

\section{Materials and Methods}

\subsection{Experimental Procedure}

Rats were obtained from Harlan Inc. (Rehovot, Israel) and were kept at 12 hrs light/12 hrs dark conditions. They were fed on Purina and water was given ad libitum. A total of 42 Wistar male rats were divided into two groups: one group (29 rats) of 2-3-month-old rats (weighing 200 - 250 gr); and another group (13 rats) of 7-month-old rats (weighing $400 \mathrm{gr}$ ). The rationale of using different ages was to explore whether induction of stem cells in the BM by LLLT takes place in old rats and in young rats. 
All the experimental procedures were approved by the Animal Care Committee of Tel-Aviv University. Rats were anesthetized with Avertin $(1 \mathrm{ml} / 100 \mathrm{~g}$ body weight I.P.) and a longitudinal $(2 \mathrm{~cm})$ incision was performed in the lateral pelvic part of the body through the skin and muscles. Left or right kidney (randomly selected) of each rat was exposed, as well as the renal artery. Ischemia-reperfusion injury (IRI) was performed by clamping the renal artery about $5 \mathrm{~mm}$ from its entry into the kidney. The contra-lateral kidney in each rat remained intact. Occlusion was verified by observation of no blood flow in the artery and cyanotic color of kidney, compared to the intact kidney. Following ischemia, while rats were still under anesthesia, reperfusion was performed by gentle removal of the clamp and visualization (under a microscope) of the resumption of blood flow in the renal artery. The rats were then divided randomly into two groups. In the group of 2-3-month-old rats 17 animals underwent IRI for $15 \mathrm{~min}$, while in 12 animals IRI was induced for $30 \mathrm{~min}$. In each group 8 rats received LLLT to the bone marrow 1 and 7 days post-IRI, and all rats were sacrificed 2 weeks later. In the group of 7-month-old rats, 8 animals served as control and 5 received LLLT.

In order to track kidney injury markers in the blood we performed IRI to 47 rats (of the total 89) for 20 min to each kidney and applied laser application as described above. Blood samples were collected from the tail vein under anesthesia for determination of creatinine, blood urea nitrogen (BUN), leukocytes, and c-kit+ cells in the blood at 1, 2, and 7 days post-IRI. The blood tests for creatinine and BUN were performed by American Medical Laboratories (Herzeliya, Israel).

\subsection{Laser Application}

Following induction of IRI rats were randomly assigned to a laser-treated or control, non-laser-treated, group. A diode (Ga-Al-As) laser, wavelength $804 \mathrm{~nm}$ with a tunable power output of maximum of $400 \mathrm{~mW}$ was used (Lasotronic Inc., Zug, Switzerland). The laser device was equipped with a metal-backed glass fiber optic (1.5 mm diameter). An infrared viewer (Lasotronic Inc. Zug, Switzerland) and infrared-sensitive detecting card (Newport, Inc., Irvine, CA) were used to determine the irradiation area.

In all groups 1 and 7 days post-IRI induction, the left or right tibia bone (chosen randomly) was exposed. In the laser-irradiated group the distal tip of the fiber optic was applied to the flat medial aspect of the exposed tibia ( $5 \mathrm{~mm}$ distal to the knee joint) delivering a power output of $10 \mathrm{~mW} / \mathrm{cm}^{2}$ for $100 \mathrm{sec}$ (power density of $1 \mathrm{~J} / \mathrm{cm}^{2}$ ) to the BM. Control rats underwent the same procedure as the laser-irradiated group but the laser was not turned on. It should be noted that we specifically timed application of the LLLT for 24 hrs post-IRI, in order to determine the ability of LLLT to induce stem cells in the BM for the benefit of the kidney, when treatment postkidney IRI is delayed. Thus, one can assume that treating the BM with laser application may, at least in part, mimic treatment of chronic renal failure and not treatment suitable only for immediate application following acute renal failure. Two weeks post-IRI to the kidney the rats were sacrificed and IRI and intact kidneys were removed. The kidneys were separated by longitudinal sectioning at the mid-plane of each kidney into two identical halves. One half was taken for histology (cold fixation in $4 \%$ neutral buffered formalin for 48 hours) and the other half was stored at $-70^{\circ} \mathrm{C}$ for biochemical analysis.

\subsection{Histology and Immunohistochemistry}

For histopathological evaluation sections were stained with hematoxylin-eosin, and histopathological changes were evaluated by quantitative measurements of tubular necrosis, loss of cell brush borders, and mononucleated cell infiltration. For each rat a total of 36 randomly selected areas $(500 \times 500 \mu \mathrm{m} ; 6$ areas from each of the 6 sections taken from the rat) were examined at X40 objective using a Zeiss microscope. Each area was assigned one of four levels of numerical scoring. Score 0, no damage (normal histology); score 1, tubular cell swelling, loss of brush border, and 1/3 of the examined area defined as tubular necrosis and mononucleated cell infiltration; score 2 , as score 1 , but between $1 / 3$ and $2 / 3$ of the examined area demonstrate necrosis and mononucleated cells infiltration; score 3 , as score 2, but necrosis and mononucleated cell infiltration occupying more than 2/3 of the examined area. The scoring of the histopathological data was performed by two independent observers blinded to control or laser-treated samples. Score values were expressed as mean value of score levels 1, 2 or 3 for each rat. The scores from all rats of each group (control and laser-treated) were then statistically analyzed for differences in scoring levels between the groups.

For immunohistochemistry, 8-micron thick paraffin sections were prepared from the tissue samples of each (right and left) kidney and stained using hematoxylin-eosin staining. C-kit immunohistochemical staining was 
performed on random paraffin sections in order to detect MSCs as described previously (26). Two observers, blinded to control or treated rats, analyzed the section stained for c-kit+ cells. The c-kit+ cell density was calculated by dividing the number of c-kit+ cells counted by the unit area in the total section of each kidney. The measurements were performed on six randomly selected sections of each kidney.

\subsection{Enzymatic Determinations}

Ten percent (w/v) homogenates were prepared in $0.01 \mathrm{M}$ Tris buffer containing, $0.01 \%$ Triton, $2 \mathrm{mM} \mathrm{CaCl}{ }_{2}$ and protease inhibitor cocktail (Sigma, Sant Luis, USA) from each IRI kidney or intact kidney. Succinate dehydrogenase enzymatic activity assay was determined using $0.2 \mathrm{M}$ succinate as a substrate, $0.5 \mathrm{mM}$ dichlorophenolindophenol (DCIP), and $0.1 \%$ solution of phenazin methosulfate (PMS) in $0.1 \mathrm{M}$ Tris buffer. Absorbance was read at $630 \mathrm{~nm}$ in a microplate reader spectrophotometer adjusted to zero with the blank sample (saline instead of homogenate sample).

\subsection{Flow Cytometry Analysis}

Blood samples were taken 2 and 7 days post-IRI for fluorescence-activated cell sorting (FACS) analysis. $100 \mu \mathrm{l}$ of blood were mixed with different antibodies: anti-mouse CD117 (c-kit), PE (eBioscience San Diego, USA), and rat IgG2b isotype control PE (eBioscience San Diego, USA), and used for the FACS analysis according to the manufacturer's guidelines. Forty-five min post incubation of the whole fresh blood with the relevant antibodies, $2 \mathrm{ml}$ of Fix/Lyse solution (eBioscience, San Diego, USA) were added. After mixing the suspended cells were left for $60 \mathrm{~min}$ in the dark at room temperature. Centrifugation was performed for $10 \mathrm{~min}$, supernatant was removed, and washing of the pellet was performed with $2 \mathrm{ml}$ of Flow Cytometry Staining Buffer Solution (eBioscience, San Diego, California, USA). After another centrifugation for 10 minutes the supernatant was decanted. The pellet, containing mononucleated cells, was resuspended in $200 \mu \mathrm{l}$ of flow stain buffer for FACS analysis.

\subsection{Statistical Analysis}

The SigmaStat 2.0 (Sigma, St Luis, USA) software was used for statistical analysis. Tests were performed first for normality distribution, followed by parametric (student’s t-test) test.

\section{Results}

In the group of 2-3-month-old rats the histopathological changes visible in the control, non-laser-treated, histological sections consisted mainly in tubular dilatation, loss of contour of those tubules, and necrosis, as well as some blood cells in the interstitial tissue of the kidney (Figure 1). However, in those rats that received LLLT to the BM post-IRI to the kidney, the contour of renal tubules remained clear, almost no tubular dilatation was observed, and necrosis was barely discernible. Overall, necrotic (cell infiltration) areas, tubular dilatation, and degenerative epithelium was much more prominent in the control IRI-kidneys, compared to the laser-treated IRI-kidneys. The quantitative histopathological analysis of the 15 min IRI indicated significantly higher ( $\mathrm{p}<$ 0.001) 3.6-fold scores in the control, non-laser-treated rats as compared to the laser-treated rats (Figure 2(a)). It should be noted that in this group (15 min IRI) none of the histological sections of the laser-treated rats) = reached a score of 3; while in the control, non-laser-irradiated rats, some sections did reach a score of 3. Quantitative histopathological analysis of the 30 min IRI indicated significantly higher $(\mathrm{p}<0.01) 2.37$-fold scores in the control, non-laser-treated rats compared to the laser-treated rats (Figure 2(b)). The quantitative histopathological analysis of the IRI (to one kidney for a duration of $30 \mathrm{~min}$ ) in the 7-month-old rats indicated significantly higher $(\mathrm{p}<0.002)$ 2.14-fold scores in the control as compared to the laser-treated rats (Figure 2(c)).

C-kit+ cell density in the laser-treated group of 2 - 3 month-old-rats that underwent IRI for 15 min was significantly ( $p=0.015$ ) 3.2-fold higher than in the control group (Figure 3(a)). In the intact kidney of these rats there was no significant elevation in the c-kit+ cells density over blank-control immune-stained sections (data not shown). C-kit+ cell density in the laser-treated group (2 - 3-months-old) and for 30 min IRI group was significantly ( $\mathrm{p}=0.02)$ 2.5-fold higher compared to the control group (Figure 3(b)). C-kit+ cell density in kidneys of the laser-treated group of 7-month-old rats that underwent IRI for 30 min was significantly $(p=0.045)$ 1.8-fold higher than in the control group (Figure 3(c)). 

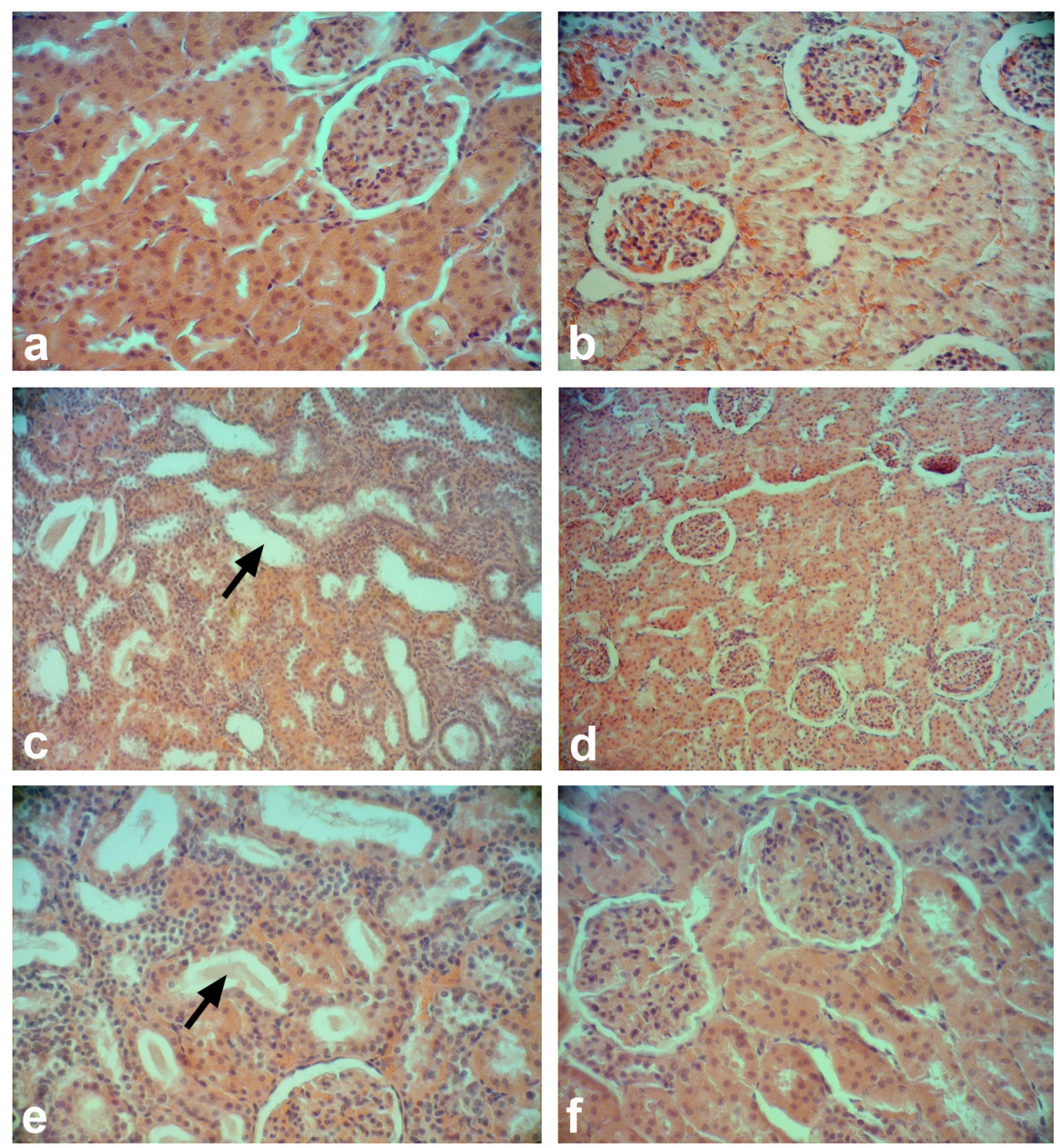

Figure 1. Representative light microscope micrographs of renal tissue in intact (a) lasertreated (b, d, f) and non laser-treated to the bone marrow (c, e) rats, 14 days post-30 min ischemic injury and reperfusion. Note a marked dilatation (arrows) of the renal tubules and necrotic areas with infiltration of mononucleated cells in control microscopic slides as compared to a minor dilatation of the renal tubules in the laser-treated rats. Magnifications are $\mathrm{a}, \mathrm{b}$, e and $\mathrm{f}$ are $\times 180$ and $\mathrm{c}, \mathrm{d} \times 100$.

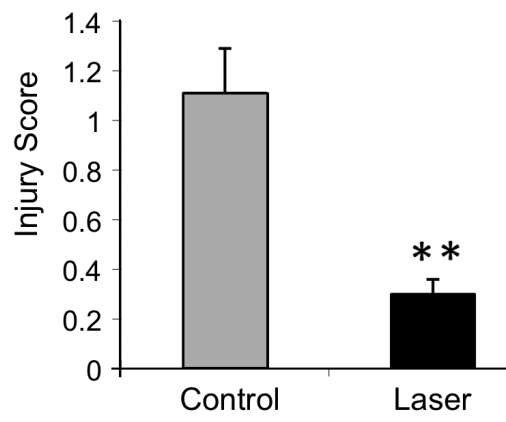

(a)

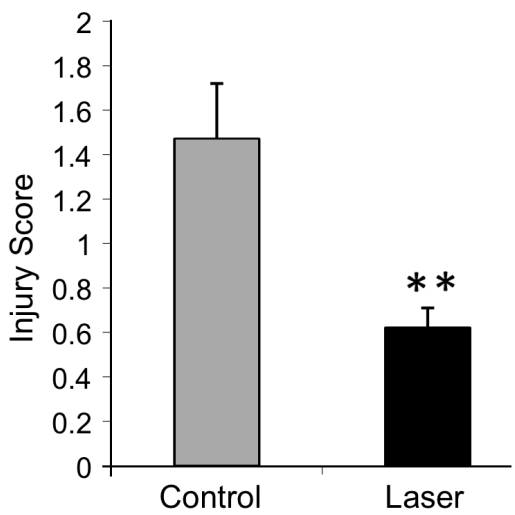

(b)

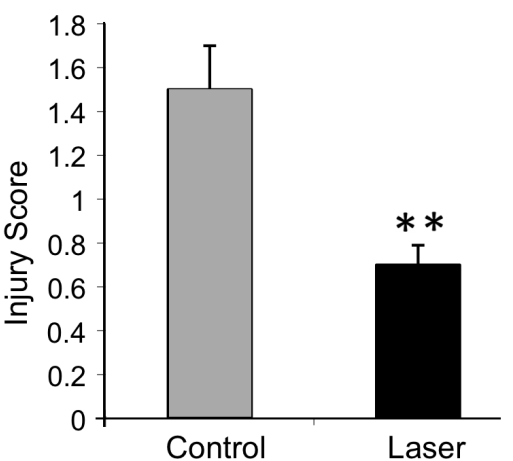

(c)

Figure 2. Effect of LLLT application to the bone marrow on the histopathological features of the kidney as reflected in the arbitrary score in non laser (open column) and laser-treated (solid column) rats. Results from 2-3-month-old rats that underwent 15 and 30 min IRI are presented in (a) \& (b) respectively. Results from 7 -month-old rats are presented as (c). ${ }^{* *} \mathrm{p}<0.01$. 


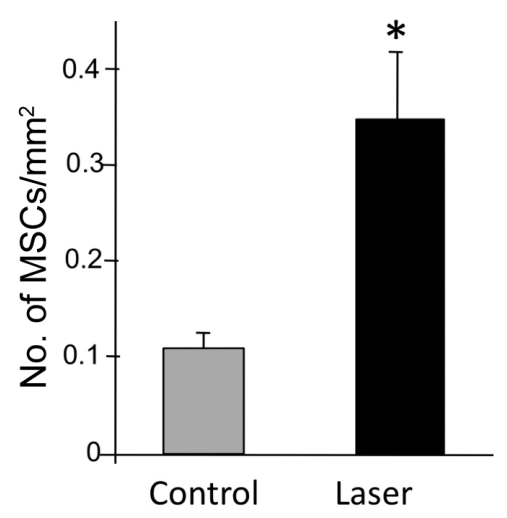

(a)

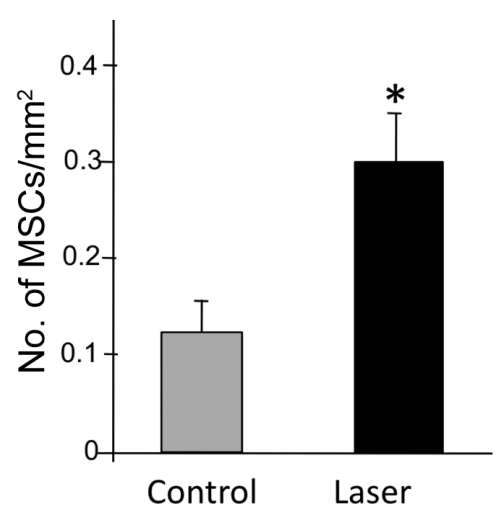

(b)

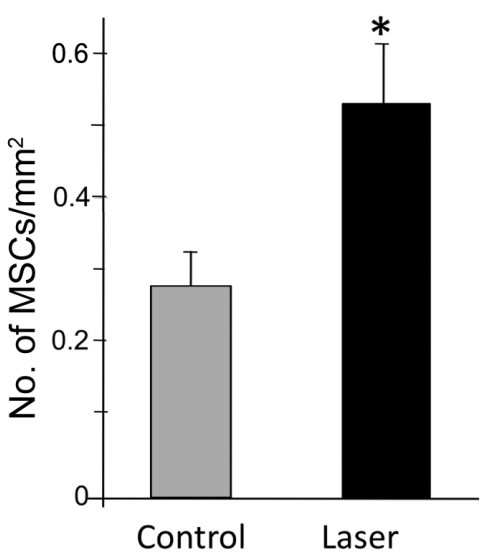

(c)

Figure 3. Effect of LLLT application to the bone marrow on the density of c-kit+ in the 15 min (a) or 30 min (b) injured IR kidneys in the non laser treat groups (open column), and laser-treated 3-month-old rats (solid column). In (c) are results from 7-month-old rats (15 min of IR-injury). Results are mean \pm SEM of 8 rats in each column. ${ }^{*} \mathrm{p}<0.05$.

In the 2-3-month-old rats the SDH results indicate that following 15 min of IRI, laser application to the BM caused a significant $(\mathrm{p}=0.02) 1.5$-fold elevation in electron transfer as compared to the control group (Figure 4(a)); while following $30 \mathrm{~min}$ of IRI, laser application to the BM caused a significant ( $=0.04$ ) 1.5-fold elevation in electron transfer as compared to the control group (Figure 4(b)). In the 7-month-old rats the SDH results indicate that following $30 \mathrm{~min}$ of IRI, laser application to the BM caused a significant ( $\mathrm{p}=0.02) 2$-fold elevation in SDH activity as compared to the control group (Figure 4(c)).

In the 20 min IRI, in the two-kidneys experiment, the creatinine levels in the blood of the control, non-lasertreated rats was high at 1 and 2 days post-IRI and decreased to a level of $0.5 \pm$ at 7 days post-IRI (Figure 5). In the laser-treated rats the level of creatinine was low $(0.6$ and $0.65 \mathrm{mg} / \mathrm{dl})$ at 1 and 2 days post-IR, respectively; and further decreased to $0.42 \mathrm{mg} / \mathrm{dl}$ at 7 days post-IRI. At the latter time interval the creatinine level was significantly ( $\mathrm{p}=0.04) 1.23$-fold lower than in the control group. The nitrogen urea content (BUN) in the blood demonstrated a similar trend to creatinine (Figure 6). It was significantly $(\mathrm{p}=0.04)$ lower in the laser-treated rats already at 2 days post-IRI to the kidneys, and highly significant $(\mathrm{p}<0.005)$ at 7 days post-IRI compared to the levels of BUN in the non-laser-treated rats. The reduction comprised 2.2-fold and 1.5-fold that of the control rats at 2 and 7 days post-IRI respectively.

FACS analysis of the blood of the rats that underwent $30 \mathrm{~min}$ of IRI showed that total percentage of C-kit+ cells in the blood out of the total mononucleated nuclei in the blood was 2.1-fold significantly ( $p>0.01$ ) higher in the laser-treated groups compared to the control 5 days post-IRI (Figure 7).

\section{Discussion and Conclusion}

The present study indicates that LLLT has reno-protective effects post moderate IRI to the rat kidney. The findings corroborate our recent study on the beneficial effects of induction of stem cells in the BM by LLLT to the rat post-myocardial infarction (MI) [26] [27]. The results of the current study also demonstrate that LLLT to the BM caused a significant increase in cell density of immuno-positive c-kit cells in the targeted injured organ (kidney). This is in accordance with a similar phenomenon following LLLT to BM in the infarcted area of the rat heart 3 and 6 weeks post-MI.

It can be hypothesized that LLLT induced proliferation of MSCs in the BM, as shown by us previously [2]. These cells subsequently migrated via the blood circulation to the kidney and populated it to a higher extent than in the non-laser-treated rats. Indeed, the results of the FACS analysis in the present study indicate that the density of c-kit+ cells in the blood of the laser-treated rats was significantly higher post-LLLT application than in the control, non-laser-treated rats. It is suggested that at least some of the stem cells may secrete various growth factors that may contribute to a better restoration and preservation of the cells in the kidneys following the ischemic insult. This mechanism of paracrine secretion by stem cells used in a cell-based therapy approach for the ischemic heart has been previously suggested [29]. The higher SDH activity in the IR-injured kidney that received the laser treatment to the $\mathrm{BM}$, as compared to control non-laser-treated rats, may indicate a better pre- 
servation of mitochondria in these kidneys. Furthermore, a better mitochondrial function and higher production of ATP in the kidney of the laser-treated rats as found in the ischemic heart and brain post-LLLT [18] [22] may contribute to restoration of kidney function post-IRI. The possibility that BM progenitor cells can induce endogenous stem cells in an ischemic organ was also recently found following injection of progenitor cells into the ischemic heart [29] [30]. All the above processes could contribute in conjunction to the restoration of renal tubular function post-renal-failure. Indeed, in those rats that were laser-treated to the BM, the quantitative analysis of histopathological features showed a significantly lower score as compared to the non-laser-treated rats, following IRI to the kidney. The overall beneficial effect of LLLT to the BM on the IRI rats was evident also in the blood tests for kidney function. The levels of BUN in the blood of laser-treated rats were significantly $55 \%$ and $38 \%$ lower than in the non-treated rats at 2 days and 7 days respectively post-IRI to the kidney. Accordingly, creatinine level in the blood was $20 \%$ significantly lower $(\mathrm{p}=0.04,1.2$-fold $)$ in the laser-treated group as compared to the control. This difference in creatinine level was evident only at 7 days post-IRI, since the effect of the laser-induced stem cells on the recovery of glomerular filtration may be delayed in the IRI kidneys. Indeed a similar delayed effect was found in rat hearts treated by LLLT to the BM post-myocardial infarction (MI). Elevated blood vessels density was observed only 7 days post-MI [20].

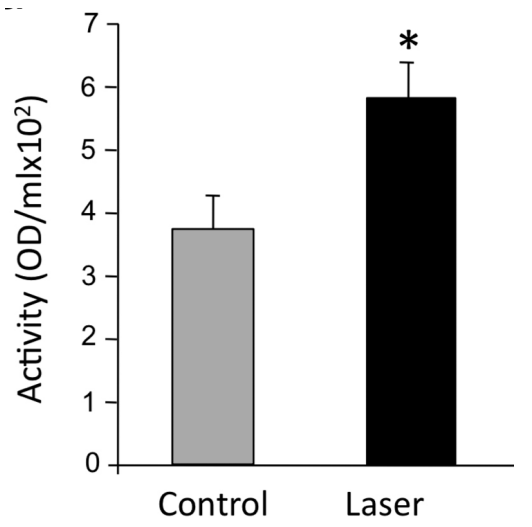

(a)

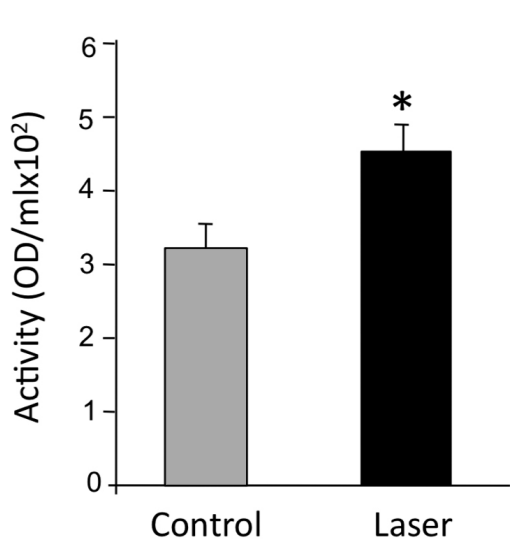

(b)

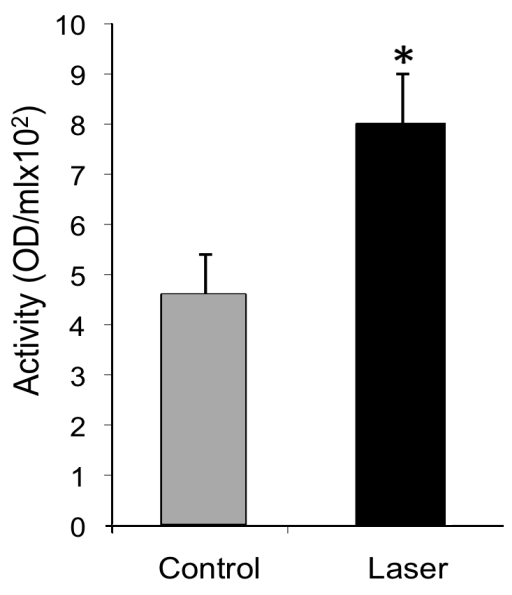

(c)

Figure 4. Effect of LLLT application to the bone marrow on SDH enzymatic activity in the 15 min (a) and 30 min (b) IRI kidneys of 2-3-month-old (a, b) or 7-month-old (c) rats in the non laser treated (open column) and laser-treated groups to the BM group (solid column). Results are mean \pm SEM of 8 rats in each column. ${ }^{*} \mathrm{p}<0.05$.

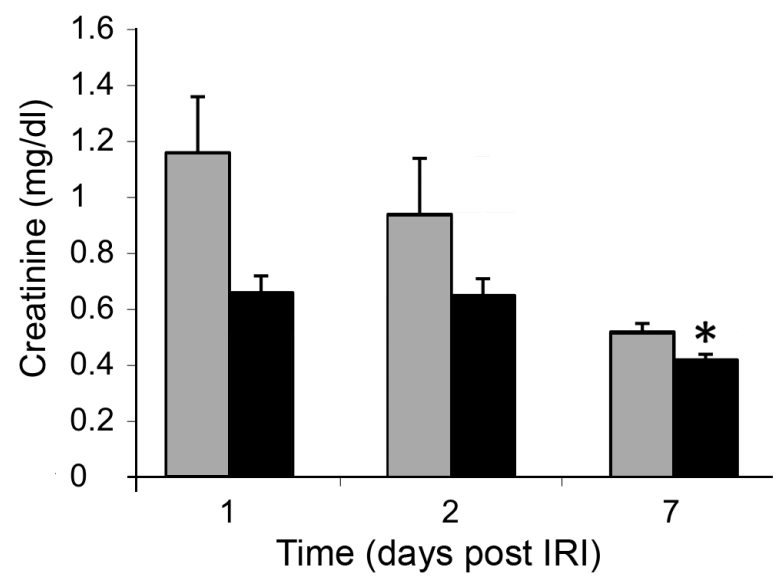

Figure 5. Effect of LLLT application to the bone marrow on creatinine levels at different time intervals in the $30 \mathrm{~min}$ IRI kidneys of 2-3-month-old rats. Control groups (open column) and laser-treated to the BM groups (solid column). Results are mean \pm SEM of $7-8$ rats in each column. ${ }^{*} \mathrm{p}<0.05$. 


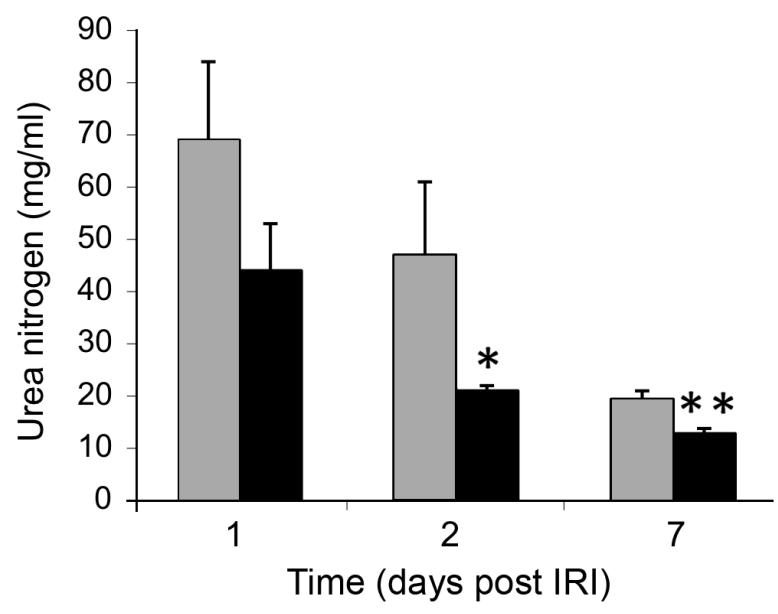

Figure 6. Effect of LLLT application to the bone marrow on blood urea nitrogen (BUN) levels in the 30 min IRI kidneys of 2-3-month-old rats at different time intervals. Control groups (open column) and laser-treated to the BM groups (solid column). Results are mean \pm SEM of $7-8$ rats in each column. ${ }^{*} \mathrm{p}<0.05$ and ${ }^{* *} \mathrm{p}<0.01$.

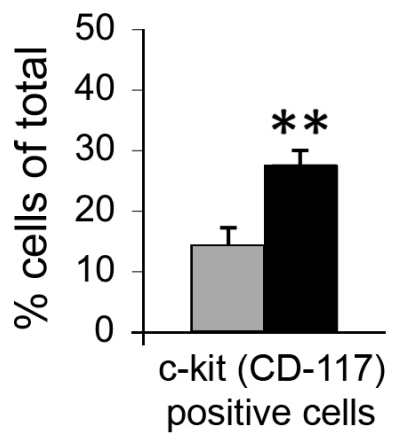

Figure 7. Effect of LLLT application to the bone marrow on CD-117 levels in circulating blood in the 30 min IRI kidneys of 2-3-month-old rats in non laser (open column) and lasertreated rats (solid column) 5 days post IRI. Results are mean \pm SEM of 7 - 8 rats in each column. ${ }^{* *} \mathrm{p}<0.01$.

Another aspect of the present study is the ability of LLLT to induce stem cells even in the BM of mature (7-month-old) rats relative to the 3-month-old ones, resulting in a beneficial effect to the IRI kidney. It is known that the number of stem cells in general decreases with age in the BM of long bones in rats, where the fat content increases [31]. Here we have demonstrated that the number of c-kit cells that homed in on the kidney in the 7-month-old laser-treated rats was significantly higher than in those that did not receive the laser treatment to their BM. Furthermore, the quantitative histopathology analysis indicated significant structural preservation of the IRI in the kidneys of the laser-treated older rats over the non-laser-treated ones, similar to the phenomenon shown in the 3-month-old rats. Thus it can be postulated that applying LLLT to the entire cell population in the $\mathrm{BM}$ contributes to the beneficial effects even in older rats.

The results of the present study reinforce our recent study on the effect of LLLT application to the BM of infarcted rats, as well as the concept that induction of stem cells by LLLT to the BM may offer a novel approach in stem-cell therapy to ischemic/injured organs. It may also be suggested that following application of the LLLT to the BM, several types of stem cells or progenitor cells are induced, and that these cells act in concert when they home in on the targeted injured organ to attenuate healing processes post-injury in those organs. This approach, of the induction of several types of stem cells in the BM that will act (differentiate and/or secrete growth factors) on the targeted organ, may prove advantageous over the introduction of a single type of stem cell into an 
organ, as currently common in stem-cell therapy.

The current study may also have clinical relevance. Many pathological disorders of the kidney are associated with dysfunction of the kidney components, similar to those observed following IRI to the kidney. It may be postulated that recruitment of photobiostimulated stem cells from the BM to the pathologically impaired kidney, as described in the present study, may offer a new approach to improving kidney function. We also applied LLLT to the BM in the present study 24 hrs post moderate IRI to the kidney, in order to determine whether LLLT could reverse already ongoing degenerative/inflammatory processes. It should be noted that the application of LLLT at similar power densities as given in this study (and at even higher and more frequent doses) was found to be safe both in experimental animals [32] and in humans post-acute-stroke [33], when the LLLT was applied directly to the brain. In addition, we have recently demonstrated in a long-term study in mice that LLLT to the BM does not have a histopathological effect on the BM and other organs [34]. It can thus be assumed that

In conclusion, to the best of our knowledge the present study demonstrates for the first time a significant beneficial effect of LLLT (applied to the BM of rats) to the kidney post-moderate-IRI. The precise mechanism by which the photobiostimulated stem cells affect the kidney is not yet known, or clearly understood, but remains to be elucidated by further studies.

\section{Acknowledgements}

The authors wish to thank Ms N. Paz for editing this manuscript, Dr O. Sagi for help in performing the FACS analysis, and Mrs V. Wexler for assistance with preparation of the figures.

\section{References}

[1] Morigi, M., Benigni, A., Remuzzi, G. and Imberti, B. (2006) The Regenerative Potential of Stem Cells in Acute Renal Failure. Cell Transplant, 15, S111-S117. http://dx.doi.org/10.3727/000000006783982449

[2] Lin, F., Cordes, K., Li, L., Hood, L., Couser, W.G., Shankland, S.J. and Igarashi, P. (2003) Hematopoietic Stem Cells Contribute to the Regeneration of Renal Tubules after Renal Ischemia-Reperfusion Injury in Mice. Journal of the American Society of Nephrology, 14, 1188-1199. http://dx.doi.org/10.1097/01.ASN.0000061595.28546.A0

[3] Stokman, G., Leemans, J.C., Cleassen, N., Weening, J.J. and Florquin, S. (2005) Hematopoeitic Stem Cell Mobilization Therapy Accelerates Recovery of Renal Function Independent of Stem Cell Contribution. Journal of the American Society of Nephrology, 16, 1684-1692. http://dx.doi.org/10.1681/ASN.2004080678

[4] Cantley, L.G. (2005) Adult Stem Cells in the Repair of the Injured Renal Tubule. Nature Clininical Practice Nephrology, 1, 22-32. http://dx.doi.org/10.1038/ncpneph0021

[5] Wang, Y., Hu, F., Wang, Z.J., Wang, G.X., Zhang, Z.H., Xie, P. and Cui. S.P. (2008) Administration of Bone MarrowDerived Stem Cells Suppresses Cellular Necrosis and Apoptosis Induced by Reperfusion of Ischaemic Kidneys in Rats. Chinese Medical Journal, 121, 268-271.

[6] Stockman, G., Stroo, I., Claessen, N., Teske, G.J.D., Leemans, J.C. and Florquin, S. (2010) Stem Cell Factor Expression after Renal Ischemia Promotes Tubular Epithelial Survival. PLoS One, 21;5(12):e14386.

[7] Zarjou, A., Sanders, P.W., Mehta, R.L. and Agarwal, A. (2012) Enabling Innovative Translation Research in Acute Kidney Injury. Clinical and Translational Science, 5, 93-101. http://dx.doi.org/10.1111/j.1752-8062.2011.00302.x

[8] Togwl, F.E., and Westenfelder, C. (2012) Kidney Protection and Regeneration Following Acute Injury: Progress Through Stem Cell Therapy. American Journal of Kidney Diseases, 60, 1012-1022. http://dx.doi.org/10.1053/j.ajkd.2012.08.034

[9] Fangming, L. (2006) Stem Cells in Kidney Regeneration Following Acute Renal Injury. Pediatric Research, 59, 74R78R. http://dx.doi.org/10.1203/01.pdr.0000205156.85990.12

[10] Lange, C., Tögel, F., Ittrich, H., Clayton, F., Nolte-Ernsting, C., Zander, A.R. and Westenfelder, C. (2005) Administered Mesenchymal Stem Cells Enhance Recovery from Ischemia/Reperfusion-Induced Acute Renal Failure in Rats. Kidney International, 68, 1613-1617. http://dx.doi.org/10.1111/j.1523-1755.2005.00573.x

[11] Conlan, M.J., Rapley, J.W. and Cobb, C.M. (1996) Biostimulation of Wound Healing by Low Energy Laser Irradiation. Journal of Clinical Periodontology, 23, 492-496. http://dx.doi.org/10.1111/j.1600-051X.1996.tb00580.x

[12] Karu, T. (2007) Ten Lectures on Basic Science of Laser Phototherapy. Gragesberg Sweden. Prima Books.

[13] Karu, T. (2010) Mitochondrial Mechanisms of Photobiomodulation in Context of New Data about Multiple Roles of ATP. Photomedicine and Laser Surgery, 28, 159-160. http://dx.doi.org/10.1089/pho.2010.2789

[14] Bibikova, A. and Oron, U. (1993) Promotion of Muscle Regeneration in the Toad (Bufo viridis) Gastrocnemius Muscle 
by Low Energy Laser Irradiation. Anatomical Record, 235, 374-380. http://dx.doi.org/10.1002/ar.1092350306

[15] Bibikova, A. Belkin, A. and Oron, U. (1994) Enhancement of Angiogenesis in Regenerating Gastrocnemius Muscle of the Toad (Bufo viridis) by Low Energy Laser Irradiation. Anatomy and Embryology, 190, 597-602. http://dx.doi.org/10.1007/BF00190110

[16] Oron, U. (2006) Photoengineering of Tissue Repair in Skeletal and Cardiac Muscles. Photomedicine and Laser Surgery, 24, 111-120. http://dx.doi.org/10.1089/pho.2006.24.111

[17] Yaakobi, T., Shoshani, Y., Levkovitz, S., Rubin, O., Ben-Haim, S.A. and Oron, U. (2001) Long-Term Effect of Low Energy Laser Irradiation on Infarction and Reperfusion Injury in the Rat Heart. Journal of Applied Physiology, 90, 2411-2419.

[18] Oron, U., Yaakobi, T., Oron, A., Mordechovitz, D., Shofti, R., Hayam, G., Dror, U., Gepstein, L., Wolf, T., Haudenschild, C. and Ben-Haim, SA. (2001) Low Energy Laser Irradiation Reduces Formation of Scar Tissue Following Myocardial Infarction in Dogs. Circulation, 103, 296-301. http://dx.doi.org/10.1161/01.CIR.103.2.296

[19] Oron, U., Yaakobi, T., Oron, A., Hayam, G., Gepstein, L., Wolf, T., Rubin, O. and Ben-Haim, S.A. (2001) Attenuation of Infarct Size in Rats and Dogs after Myocardial Infarction by Low-Energy Laser Irradiation. Lasers in Surgery and Medicine, 28, 204-211. http://dx.doi.org/10.1002/lsm.1039

[20] Tuby, H., Maltz, L. and Oron, U. (2006) Modulations of VEGF and iNOS in the Rat Heart by Low Level Laser Therapy are Associated with Cardioprotection and Enhanced Angiogenesis. Lasers in Surgery and Medicine, 38, 682-688. http://dx.doi.org/10.1002/lsm.20377

[21] Oliveira, F.A., Moraes, A.C., Paiva, A.P., Schinzel, V., Correa-Costa, M., Semedo, P., Castoldi, A., Cenedeze, M.A., Oliveira, R.S., Bastos, M.G., Câmara, N.O. and Sanders-Pinheiro, H. (2012) Low-Level Laser Therapy Decreases Renal Interstitial Fibrosis. Photomedicine and Laser Surgery, 30, 705-713. http://dx.doi.org/10.1089/pho.2012.3272

[22] Oron, U., Ilic, S., De Taboada, L. and Streeter, J. (2007) Ga-As (808 nm) Laser Irradiation Enhance ATP Production in Human Neuronal Cells in Culture. Photomedicine and Laser Surgery, 25, 180-182. http://dx.doi.org/10.1089/pho.2007.2064

[23] Tuby, H., Maltz, L. and Oron, U. (2007) Low-Level Laser Irradiation (LLLI) Promotes Proliferation of Mesenchymal and Cardiac Stem Cells in Culture. Lasers in Surgery and Medicine, 39, 373-378. http://dx.doi.org/10.1002/lsm.20492

[24] Li, W.T., Leu, Y.C. and Wu, J.L. (2010) Red-Light Light-Emitting Diode Irradiation Increases the Proliferation and Osteogenic Differentiation of Rat Bone Marrow Mesenchymal Stem Cells. Photomedicine and Laser Surgery, 28, S157-S165. http://dx.doi.org/10.1089/pho.2009.2540

[25] Mvula, B., Moore, T.J. and Abrahamse, H. (2010) Effect of Low-Level Laser Irradiation and Epidermal Growth Factor on Adult Human Adipose-Derived Stem Cells. Lasers in Medical Science, 25, 33-39. http://dx.doi.org/10.1007/s10103-008-0636-1

[26] Tuby, H., Maltz, L. and Oron, U. (2011) Induction of Autologous Mesenchymal Stem Cells in the Bone Marrow by Low-Level Laser Therapy Has Profound Beneficial Effects on the Infarcted Rat Heart. Lasers in Surgery and Medicine, 43, 401-409. http://dx.doi.org/10.1002/lsm.21063

[27] Oron, U. (2011) Light Therapy and Stem Cells: A Therapeutic Intervention of the Future. Interventional Cardiology, 3, 627-629. http://dx.doi.org/10.2217/ica.11.74

[28] Tuby, H., Yaakobi, T., Maltz, L., Delarea, Y., Sagi-Assif, O. and Oron, U. (2013) Effect of Autologous Mesenchymal Stem Cells Induced by Low Level Laser Therapy on Cardiogenesis in the Infarcted Area Following Myocardial Infarction in Rats. Journal of Biomedical Science and Engineering, 6, 24-31. http://dx.doi.org/10.4236/jbise.2013.68A1003

[29] Mummery, C.L., Davis, R.P. and Krieger, J.E. (2010) Challenges in Using Stem Cells for Cardiac Repair. Science Translational Medicine, 2, 27.

[30] Hatzistergos, K.E., Quevedo, H., Oskouei, B.N., Hu, Q., Feigenbaum, G.S., Margitich, I.S., Mazhari, R., Boyle, A.J., Zambrano, J.P., Rodriguez, J.E., Dulce, R., Pattany, P.M., Valdes, D., Revilla, C., Heldman, A.W., McNiece, I. and Hare, J.M. (2010) Bone Marrow Mesenchymal Stem Cells Stimulate Cardiac Stem Cell Proliferation and Differentiation. Circulation Research, 107, 913-922. http://dx.doi.org/10.1161/CIRCRESAHA.110.222703

[31] Cristy, M. (1981) Active Bone Marrow Distribution as a Function of Age in Humans. Physics in Medicine and Biology, 26, 389-400. http://dx.doi.org/10.1088/0031-9155/26/3/003

[32] Ilic, S., Leichliter, S., Streeter, J., Oron, A., DeTaboada, L. and Oron, U. (2006) Effects of Power Densities, Continuous and Pulse Frequencies and Number of Sessions of Low Level Laser Therapy on Intact Rat Brain. Photomedicine and Laser Surgery, 24, 458-466. http://dx.doi.org/10.1089/pho.2006.24.458

[33] Zivin, J.A., Albers, G.W., Bornstein, N., Chippendale, T., Dahlof, B., Devlin, T., Fisher, M., Hacke, W., Holt, W., Ilic, S., Kasner, S., Lew, R., Nash, M., Peres, J., Rymer, M., Schellinger, P., Scheunder, D., Schwab, S., Veltkamp, R., Walker, M. and Streeter, J. (2009) Effectiveness and Safety of Transcranial Laser Therapy for Acute Ischemic Stroke. 
Stroke, 40, 1359-1364.

[34] Tuby, H., Hertzberg, E., Maltz, L. and Oron, U. (2013) Long-Term Safety of Low-Level Laser Therapy at Different Power Densities and Single or Multiple Applications to the Bone Marrow in Mice. Photomedicine and Laser Surgery, 31, 269-273. 
Scientific Research Publishing (SCIRP) is one of the largest Open Access journal publishers. It is currently publishing more than 200 open access, online, peer-reviewed journals covering a wide range of academic disciplines. SCIRP serves the worldwide academic communities and contributes to the progress and application of science with its publication.

Other selected journals from SCIRP are listed as below. Submit your manuscript to us via either submit@scirp.org or Online Submission Portal.
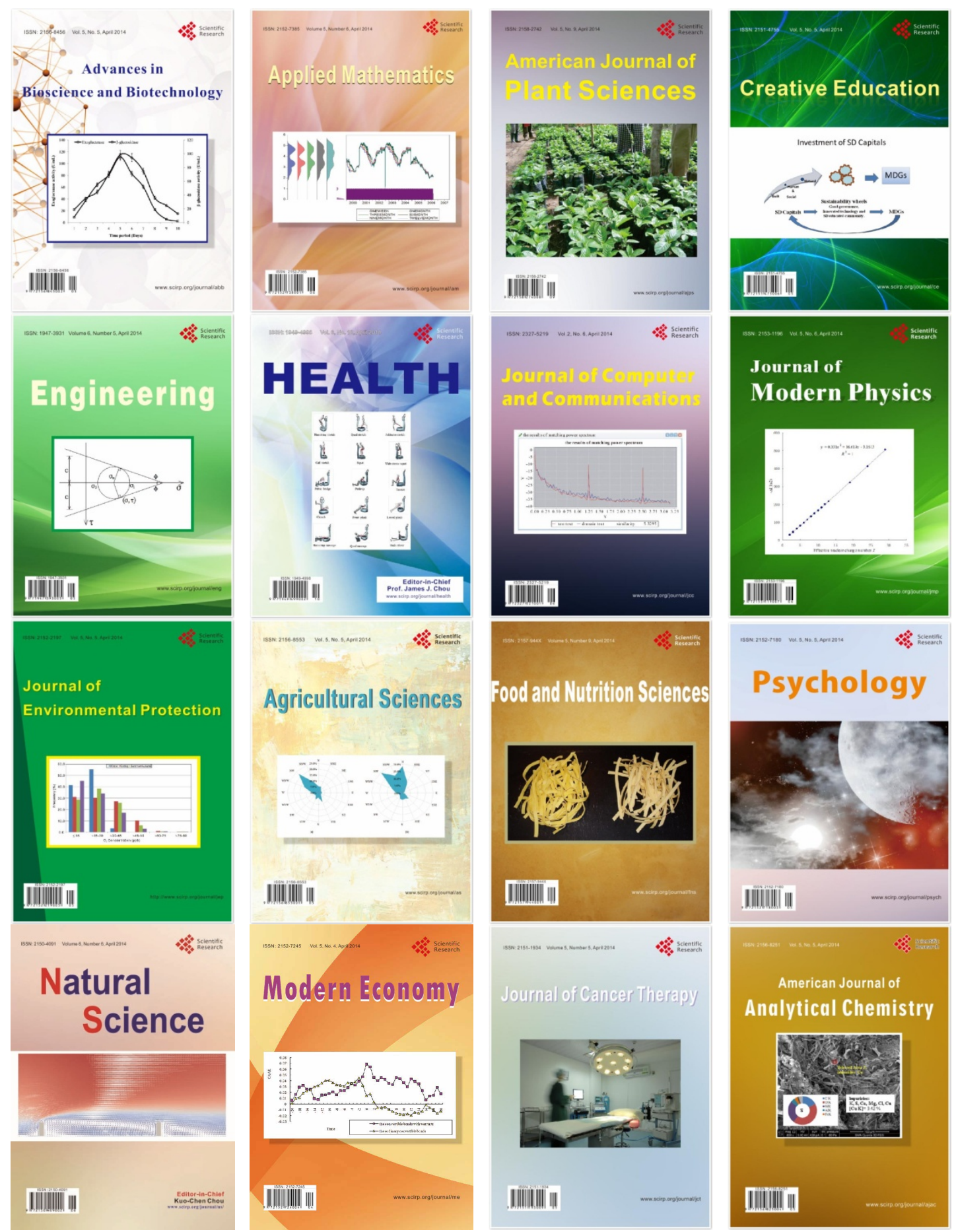